Proceedings of the 2012 Winter Simulation Conference

C. Laroque, J. Himmelspach, R. Pasupathy, O. Rose, and A. M. Uhrmacher, eds.

\title{
MODELING OF CANADIAN FORCES' NORTHERN OPERATIONS AND THEIR STAGING
}

\author{
Jean-Denis Caron \\ Yvan Gauthier \\ Ahmed Ghanmi \\ Defence R\&D Canada - Centre for Operational Research and Analysis \\ National Defence Headquarters \\ Ottawa, ON K1A 0K2, CANADA
}

\begin{abstract}
This paper summarizes modeling and simulation (M\&S) performed to assist the Canadian Forces (CF) in determining their requirements for northern operations hubs. Northern operations hubs are locations that the CF may use as staging bases for operating in the Canadian Arctic and where they may decide to maintain certain operational support capabilities, including the ability to pre-position any equipment required by contingency plans. M\&S provided insights into the number of hubs required to enable timely deployments to Canada's North. Multi-criteria decision analysis was then used to identify their most advantageous locations. The analysis considered a dozen criteria related to CF operational employment and support, many of which were assessed through $\mathrm{M} \& \mathrm{~S}$.
\end{abstract}

\section{INTRODUCTION}

\subsection{Background}

Arctic operations present unique logistical challenges due to the remoteness, harsh climate, fragile environment, and sparse population of the region. As economic activity in the Arctic continues to grow (Pelletier 2011, SN 2006), a number of safety, security, and sovereignty issues are expected to emerge. These may influence the nature, frequency, and scale of activities conducted by Canadian authorities in the region.

Except for tasks related to national defence or search and rescue, military forces in Canada do not have a leading role in Arctic operations. But in accordance with the Government of Canada's Northern Strategy (GoC 2009) and its Federal Emergency Response Plan (PSC 2011b), they must be ready to support either provincial/territorial governments or other federal government departments requesting assistance. Such requests for assistance are not uncommon since most government departments have limited capabilities for operating in the Arctic, whereas the Canadian Forces (CF) are better equipped for deploying troops and equipment across large distances and operating in harsh environments. The ability of the CF to operate domestically has also become a Government of Canada priority since the release of the Canada First Defence Strategy (DND 2008). Four out of six critical missions of the CF are now expected to be conducted domestically, including support to civilian authorities during crises such as natural disasters.

To ensure that they remain able to meet their responsibilities and will be capable of operating in the future Arctic environment, the CF have recently produced an "Arctic Integrating Concept" (DND 2010). They are also conducting various planning activities related to the development, generation, employment, and support of their capabilities in the North, which they define as Canadian territory north of $55^{\circ} \mathrm{N}$.

One element of this capability planning is the development of a hub concept for northern operations. Northern operations hubs are locations that the CF may designate as important to conduct operations in the Arctic and where they may decide to maintain certain operational support capabilities, such as the ability to 


\section{Caron, Gauthier, and Ghanmi}

pre-position equipment and resources required by contingency plans. These hubs would be primarily used as staging bases for the reception, refueling, distribution, and onward movement of troops and materiel.

\subsection{Related Work}

This kind of hub concept has been studied and implemented by the CF in the past, but primarily for expeditionary logistics. The applicability of a hub concept to northern operations was first examined in a study (Ghanmi 2010) that considered a generic deployment scenario. A more specific scenario describing the CF response to a major air disaster in the Arctic was later analyzed (Ghanmi 2011) to demonstrate how modeling and simulation $(M \& S)$ can help determine the most cost-effective hub locations. However, many relevant scenarios and decision factors were not considered by these two studies and, at the request of the $\mathrm{CF}$, additional analysis was conducted to assist them in further developing the hub concept.

\subsection{Overview}

This paper summarizes how selected portions of the analysis were performed. M\&S provided insights into the number of hubs required to enable timely deployments. Multi-criteria decision analysis was then used to identify the most advantageous hub locations. The analysis considered a dozen criteria related to $\mathrm{CF}$ operational employment and support, many of which were assessed through M\&S tools already developed for the CF. The goal of this work is not to demonstrate a new M\&S tool, but rather to illustrate how different aspects of the hub location problem were examined through $M \& S$ and how the results were combined through multi-criteria decision analysis. Partial results are presented for illustration purposes, but the complete set of results and modeling assumptions are documented in a separate report (Caron et al. 2012).

\section{POTENTIAL HUB LOCATIONS AND COMBINATIONS}

Canada's North covers a huge area roughly equivalent to the size of Europe. Although sparsely populated, it includes many airfields that could be used as forward bases for CF deployments, as illustrated in Figure 1. However, many of these airfields cannot receive some of the bigger and heavier military aircraft, and those that can may only be able to do so on a seasonal basis due to runway thaw and weather conditions. The lack of infrastructure at many airfields also prevents prolonged operations from them. Since the cost of developing new infrastructure in the Arctic can be prohibitive, any airfield potentially designated as a hub must already exist and meet minimum requirements for an array of existing CF aircraft types.

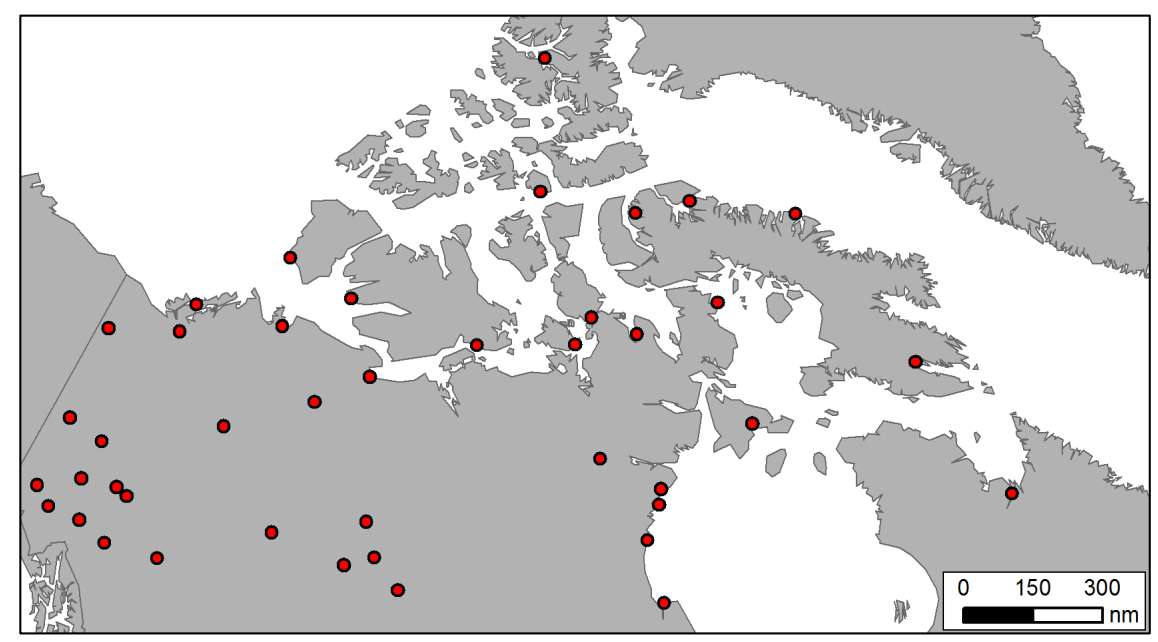

Figure 1: Airfields in Canada's North. 


\section{Caron, Gauthier, and Ghanmi}

Even if these requirements are only met by a subset of the airfields shown in Figure 1, this still implies a large number of potential hub combinations that need to be examined. Assuming only 14 (one third) of the locations in Figure 1 meet minimal CF requirements, approximately 3500 candidate combinations of 1 to 5 hubs can be generated from them.

\section{NORTHERN DEPLOYMENT SCHEMES}

It is assumed here that major disasters and contingencies for which military assistance would be requested would overwhelm first responders already in the North, and thus would require the deployment of forces from the south of the country. Such contingencies may require rapid transportation of a significant number of troops and equipment to the area of operations, in order to minimize the consequences of the events and potentially save lives.

Two schemes of deployment were modeled and are illustrated in Figure 2. First, response units could deploy by helicopter from an army base (Petawawa, Ontario in this example) directly to the event location (dashed line), and from there conduct movements between the incident location and a forward support base (FSB), which would typically be situated at the nearest airfield and support tactical operations. However, due to their limited range, helicopters may have to refuel multiple times on their way to the Arctic. Their speed, which is relatively low compared to fixed-wing aircraft, may also be an issue for reaching remote locations quickly.

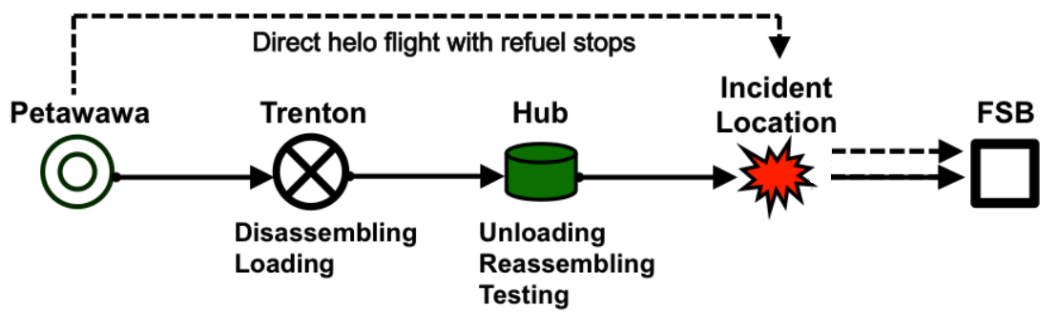

Figure 2: Example of two deployment schemes from Petawawa.

Alternatively, fixed-wing transport aircraft could be used. As illustrated by the bottom line (solid line), helicopters could initially ferry response units to the CF main airlift base (Trenton, Ontario). Assuming helicopters are critical assets for conducting movements between the incident location and the FSB, they would have to be disassembled and loaded into a transport aircraft at Trenton. From there, they would be flown to a hub from where the operation would be staged. Given appropriate infrastructure and resources at the hub, helicopters could be quickly reassembled and tested before self-deploying to the incident location, where no runway may exist. In this case, fixed-wing airlift would provide a means of traveling long distances more quickly and without refuel stops, but the helicopter disassembly and re-assembly would take a certain amount of time.

Which of the two deployment schemes is the fastest? This depends on multiple factors, especially the location of the incident and aircraft speeds. The preparation times at the main base (for disassembly and loading) and at the hub (for unloading, reassembly, testing) are also key factors. Through M\&S, the two deployment schemes can be systematically compared to each other for a set of potential incident locations, potential hub locations, and potential FSB locations.

Beyond the two deployment schemes illustrated in Figure 2, it may also be possible to deploy directly to an FSB instead of a hub. However, it may not be possible to use certain types of aircraft at these smaller airfields, and the lack of infrastructure may create additional delays. This has been analyzed in a separate work (Caron and Gauthier 2011) that compared a larger set of deployment schemes. It concluded that the two illustrated in Figure 2 would enable the quickest response at most locations. 


\section{Caron, Gauthier, and Ghanmi}

\section{SELECTION CRITERIA AND METRICS}

A dozen of criteria relevant to the $\mathrm{CF}$ were identified and used to rank potential hub locations and combinations. The criteria, which are listed in Table 1, focus exclusively on operational employment effectiveness and operational support capabilities. Other relevant criteria, such as cost issues, were excluded from the analysis but examined separately by the CF.

Table 1: List of criteria and associated metrics.

\begin{tabular}{|l|l|}
\hline Criteria & Metrics \\
\hline Operational Employment Effectiveness & Initial response time \\
\hline 1. Utility for air disaster response & Initial response time \\
\hline 2. Utility for maritime disaster response & Initial response time \\
\hline 3. Utility for natural disaster (floods, fires, earthquakes) response & Initial response time \\
\hline 4. Utility for strategic airlift anywhere in the North (other contingencies) & SAR utility score \\
\hline 5. Utility for Search and Rescue (SAR) basing & NORAD utility score \\
\hline 6. Utility for NORAD basing & Serviceability rate \\
\hline 7. Serviceability of airfield (weather) & \multicolumn{2}{|l|}{} \\
\hline Operational Support Capabilities & Subject-matter expert rating \\
\hline 8. Runway condition & Subject-matter expert rating \\
\hline 9. Fuel capacity and availability & Subject-matter expert rating \\
\hline 10. Infrastructure capability and capacity & Subject-matter expert rating \\
\hline 11. Maintenance and contracting capability & Subject-matter expert rating \\
\hline 12. Sustainment capability and capacity
\end{tabular}

\subsection{Operational Employment Effectiveness}

Criteria 1 to 4: Response time - The CF must be able to rapidly deploy wherever incidents occur. Criteria 1 to 4 serve to measure the timeliness of the $\mathrm{CF}$ response to various types of contingencies, including air disasters, maritime disasters, natural disasters, and other potential contingencies.

The metric used to rank potential hub combinations is the "initial response time", which is defined here as the total time required for forces to deploy. Going back to the example of Figure 2, this is the time between when forces leave Petawawa and the time when a first (one-way) sortie is completed between the incident location and the closest FSB. Although the arrival time to the incident location is the most important component of the response time, the time to complete the first sortie to an FSB is included to account for the distance between the incident location and the closest FSB (in some instances, assets may be required to stop by a FSB before going to the incident location, and that extra component accounts for that possibility). Note that the hub and the FSB may be the same if the airfield to closest to the incident location happens to be a hub. Note also that follow-on back-and-forth movements between the FSB and the incident location are not considered to be part of the initial response and are not modeled here.

This initial response time can be formulated as follows. Let $n$ be the number of hubs, $i(i=1, \ldots, n)$ the index of a particular hub, $m$ the number of incident locations, $j(j=1,2, \ldots, m)$ the index of an particular incident location, $p$ the number of FSBs, and $k(k=1,2, \ldots, p)$ the index of an individual FSB. Let $v_{a}$ and $v_{h}$ be the fixed-wing aircraft speed and the helicopter speed, respectively. Let $d_{i}$ be the great circle distance between Trenton and hub $i, d_{0}$ the distance between Petawawa and Trenton, $d_{i j}$ the great circle distance between hub $i$ and location $j$, and $d_{k j}$ the great circle distance between FSB $k$ and location $j$. Let $\ell$ be the helicopter preparation time that includes the time required for disassembling and loading the helicopter at Trenton, and the time required for unloading, reassembling and testing the helicopter at a given hub. Let $f_{i j}$ be the helicopter total refueling time for the lift between hub $i$ and location $j$ and $f_{k j}$ be refueling time for the lift between location $j$ and FSB $k$ (closest to incident location). 


\section{Caron, Gauthier, and Ghanmi}

The response time $T_{i j}$ for incident location $j$ using hub $i(i \geq 1)$ is given by:

$$
T_{i j}=\frac{d_{0}}{v_{h}}+\ell+\frac{d_{i}}{v_{a}}+\frac{d_{i j}}{v_{h}}+f_{i j}+\min _{k}\left(\frac{d_{k j}}{v_{h}}+f_{k j}\right),
$$

and the optimal response time $T_{j}$ for location $j$ is the minimum response time over all potential hubs, or the time to fly to the incident and then the FSB directly from Petawawa $T_{\text {direct }}$ :

$$
T_{j}=\min _{i=1 \ldots n}\left(T_{i j}, T_{\text {direct }}\right)
$$

The airlift model used for this work calculates $T_{j}$ by performing an exhaustive search of the minimum time over all potential flight paths.

The average response time over all incident locations $\bar{T}$ is calculated by giving each location a certain weight $\left(0 \leq w_{j} \leq 1\right)$ proportional to the expected probability that an event will occur at location $j$ and require $\mathrm{CF}$ assistance.

For criteria 1 to 3 , the weights $w_{j}$ are determined from historical data. Since there has been very few air disasters in the North, potential incident locations are weighted proportionally to traffic densities north of $60^{\circ} \mathrm{N}$ (instead of $55^{\circ} \mathrm{N}$ due to dataset limitations) for aircraft with nine passengers or more, as presented in Figure 3a. The maps of Figure $3 \mathrm{~b}$ and Figure $3 \mathrm{c}$ show where significant maritime disasters and natural disasters have occurred in the past, and weights are assigned proportionally to their historical densities. Criterion 4 accounts for the possibility of having to deploy forces anywhere in the North, and in this case the same weight is given to all locations.

Criterion 5: SAR basing utility - The CF is responsible for the effective operation of the aeronautical and maritime SAR system in Canada. None of the primary fixed-wing SAR bases (Comox, Winnipeg, Trenton, Greenwood) are located in the Arctic. Recent studies (Bourdon 2005, 2011) have shown that given only four fixed-wing SAR bases, existing locations provide an effective coverage since the spatial distribution of SAR incidents is strongly biased toward the southern part of the country, as shown in Figure 4. In fact, less than $1 \%$ of all SAR incidents occurring in Canada currently require the CF to operate north of $55^{\circ} \mathrm{N}$ (DND 2011). But as the population and economic activity of the Arctic continue to grow, it is conceivable that SAR assets may eventually have to be based there, either on a seasonal or permanent basis.

Since hubs could offer basic infrastructure for SAR basing, a criterion accounts for this in comparing potential hub locations. Their relative utility was compared by answering the following question: if an additional SAR base were to be established in the North, where would it be best located?

Such questions on optimal SAR basing are frequently examined by the CF and M\&S tools already exist to answer them. One model (Bourdon 2011) calculates a "SAR score" for each possible combination of SAR bases. Combinations that obtain the best scores are those that maximizes the number of historical incidents falling within SAR aircraft range, while minimizing the response time to these incidents.

Using this SAR model, each potential hub location was added to the current set of fixed-wing SAR bases at Comox, Winnipeg, Trenton, and Greenwood and its SAR score was computed. The same modeling assumptions as those used in a recent study (Bourdon 2011) conducted for the Royal Canadian Air Force (RCAF) were used. The SAR incident distribution in input to the model is the one shown in Figure 4, which includes all SAR incidents that Government of Canada organizations had to respond to in the years 2000 through 2004.

Criterion 6: NORAD basing utility - The main role of the North American Aerospace Defense Command (NORAD) is to prevent air attacks against North America and safeguard the sovereign airspaces of the United States and Canada by responding to unknown and unauthorized air activity either approaching or operating within these airspaces. This occasionally requires positioning fighter aircraft at forward locations 


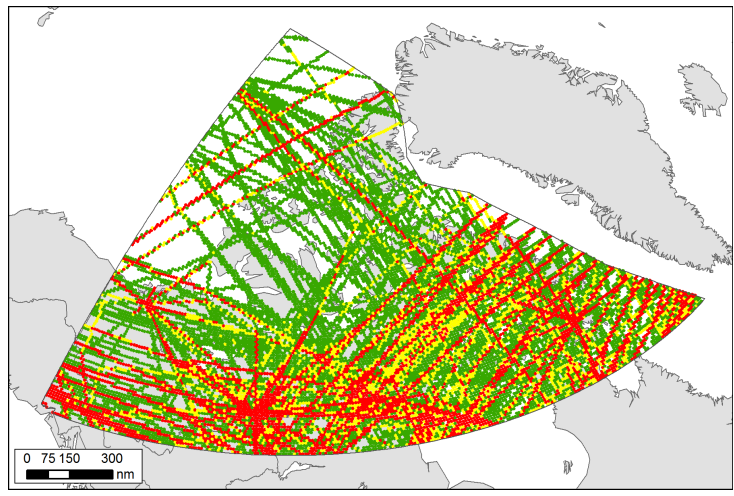

a) Sample of flight paths

(Source: Scales 2007, NAV Canada)

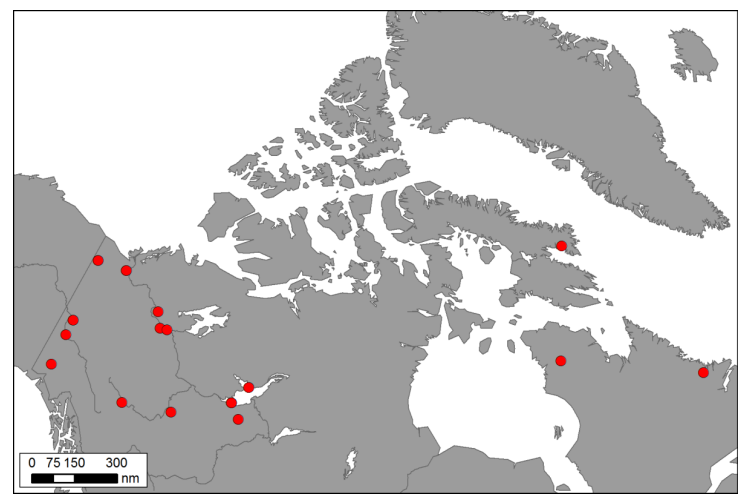

c) Significant natural disasters (Source: PSC 2011a)

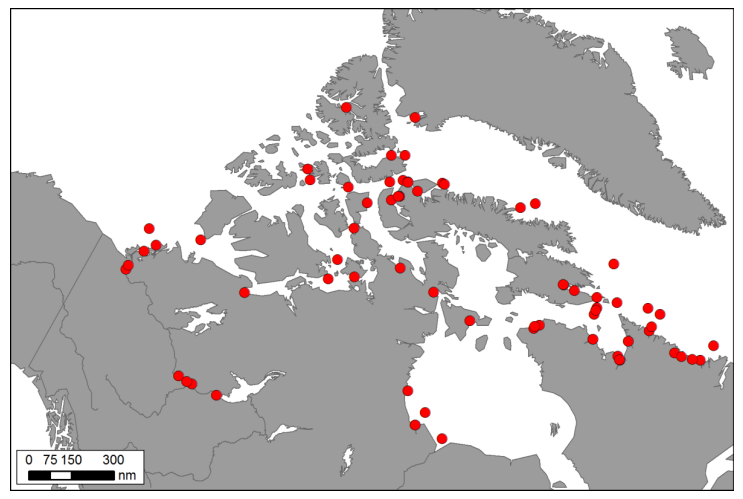

b) Significant maritime incidents (Source: Arctic Council 2009)

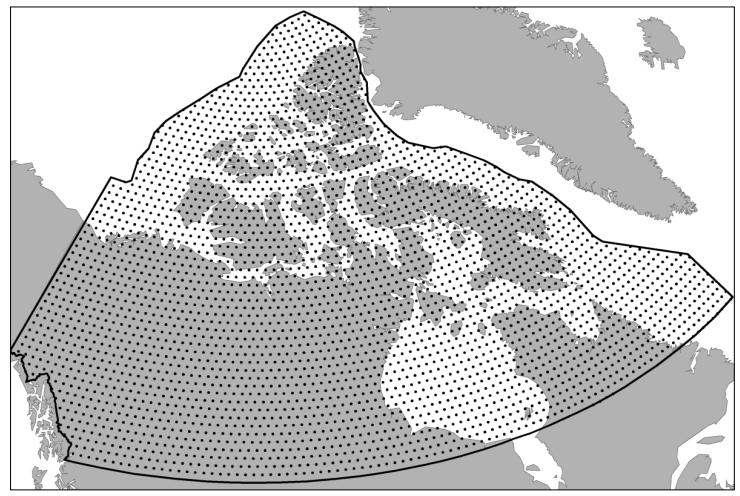

d) Uniform incident distribution

Figure 3: Historical/potential incidents distributions used for weighting locations in criteria 1 to 4 .

in the North. Criterion 6 accounts for the potential usage of hubs as forward operating locations for NORAD.

A "NORAD utility score" for each hub combination was calculated from an existing fighter basing model. The model was specifically developed to help the A3 Fighter Division of the Canadian NORAD Region in providing recommendations on infrastructure investment to the RCAF (Carson and Caron 2010). The model ranks and compares the utility of various bases in fulfilling NORAD's missions.

Criterion 7: Serviceability - Airfield serviceability is looked at from a weather perspective, that is, by determining how frequently meteorological conditions are good enough for air operations to occur (aircraft serviceability and maintenance issues were not considered). The serviceability of an airfield is defined here as the frequency with which the following two conditions are simultaneously met:

1. Cloud ceiling greater than 500 feet (ceiling being the lowest altitude, measured above ground, at which the sky is either overcast or broken).

2. Visibility greater than one statute mile (visibility being the distance at which objects of suitable size can be seen and identified).

These limits were set in consultation with $\mathrm{CF}$ planners, considering visual flight rules requirements for helicopters in uncontrolled airspace such as the Arctic. The frequency with which these two criteria are simultaneously met at each candidate hub location was estimated from hourly weather observations provided by (Environment Canada 2011) for a five-year period. 


\section{Caron, Gauthier, and Ghanmi}

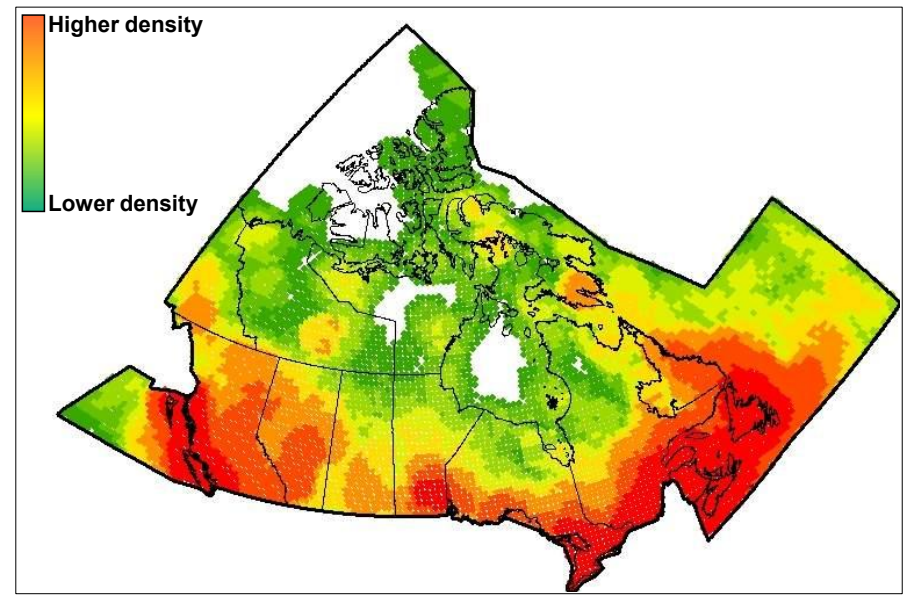

Figure 4: Historical distribution of SAR incidents (Source: Bourdon 2011).

\subsection{Operational Support Capabilities}

Criteria 8 to 12 related to operational support capabilities capture existing airfield capabilities and capacities, as well of other characteristics of the communities near which these airfields are located. The specific criteria that were assessed are described below.

- Runway condition: Quality of the runway at the airfield;

- Fuel capacity and availability: Capacity to store and supply fuel, and to make it readily available for various $C F$ aircraft requirements;

- Infrastructure capability and capacity: Quality of the infrastructure at airfield location or in the adjacent community, taking into account factors such as ramp space, warehousing capacity, airfield services (e.g., air control, de-icing, unloading, fuelers, stairs), communication capabilities, lodging facilities, hangars, and other infrastructure;

- Maintenance and contracting capability: Potential for maintenance/contractor support at the airfield location or in the adjacent community. This includes the availability of contractual support, mechanical support, infrastructure support, food support, firefighting support, and other factors;

- Sustainment capability and capacity: Quality and capacity of the location/community to sustain routine operations involving maritime, land, or air assets. This considers factors such as proximity to a port facility, a rail facility, the quality of the road network, and the proximity to areas where routine missions frequently take place.

While employment effectiveness criteria were assessed on the basis of quantitative models, the support criteria were assessed by subject-matter experts from the CF using qualitative rating scales (e.g., Very Good, Good, Poor). Each criterion was first assessed individually, and then combined into a global score representing the overall quality of candidate locations in terms of operational support capabilities.

\section{MULTI-CRITERIA DECISION ANALYSIS}

The problem of identifying the most advantageous hub combinations can be viewed as a typical multicriteria decision analysis (MCDA) problem where the alternatives to be ranked correspond to the possible hub combinations. CF guidance was that hub selection should be primarily based operational employment effectiveness and therefore, a two-step approach was used.

First, the combinations were ranked based on the operational employment effectiveness offered by their locations (criteria 1 to 7). This ranking was done by calculating the following weighted score: 


\section{Caron, Gauthier, and Ghanmi}

$$
u_{i}=\sum_{c=1}^{7} \lambda_{c} s_{i c} ; \forall i
$$

where $s_{i c}$ is the score of combination $i$ with respect to criterion $c$ (re-scaled on a $0-1$ interval) and $\lambda_{c}$ is the weight of criterion $c$. Various sets of weights were used to assess how sensitive solutions are to them.

Second, amongst the top-performing solutions, the combinations with the best operational support capabilities (criteria 8 to 12) were identified. Note that the objective of the MCDA was not to recommend a single combination of hub locations, since the analysis only considered a limited set of decision factors. Rather, the objective was to inform CF capability planning by identifying the top-performing combinations and understanding to what factors these combinations are the most sensitive.

\section{EXAMPLES OF RESULTS}

\subsection{Response Times vs. Number of Hubs}

The average initial response time $\bar{T}$ provided by the top-performing combinations identified through MCDA was calculated. The results are presented in Figure 5a for combinations of one to five hubs. The graph also includes the response time for zero hubs, which corresponds to the average response time for helicopters deploying directly from Petawawa to potential incident locations. For example, the initial response time of self-deployed helicopters to maritime incident locations (shown in Figure 3b) is, on average, approximately 21 hours but gets lower as hubs are added. The reduction in response time is significant when going from zero to one hub, and from one to two hubs, but with three hubs or more response times do not improve significantly. Diminishing returns are also noticeable in Figure $5 \mathrm{~b}$, which shows the percentage of the incidents that can be reached within 24 hours as a function of the number of hubs per combination.

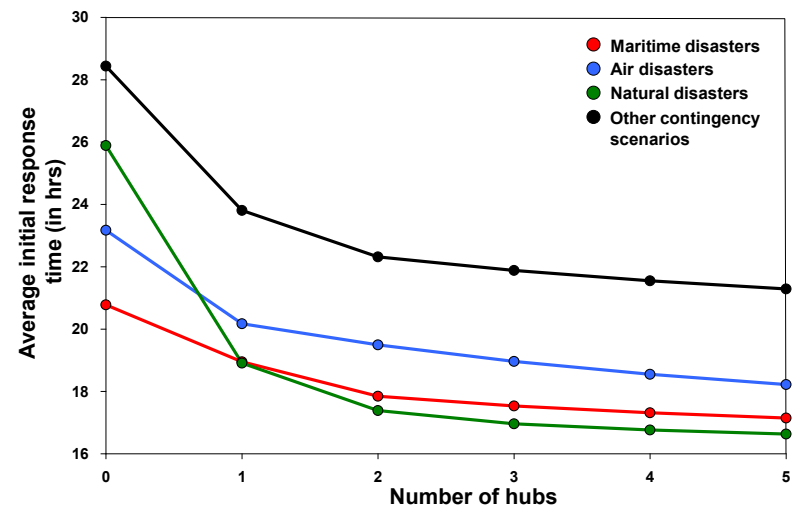

a) Average initial response time from Petawawa

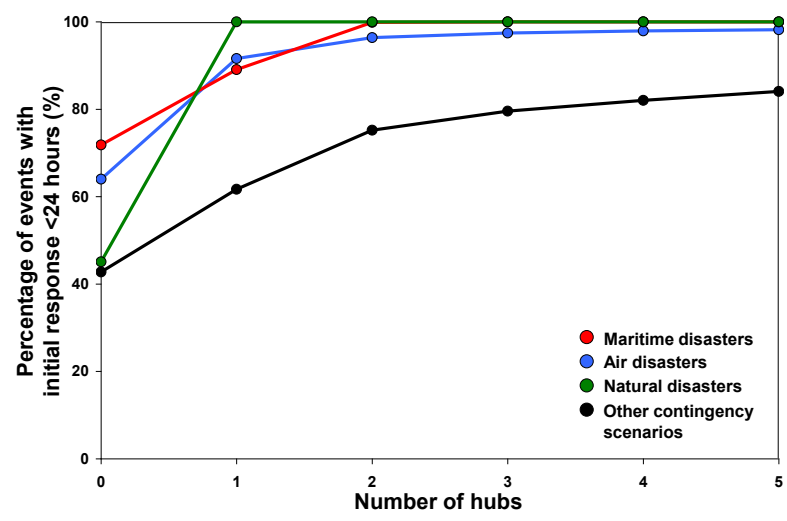

b) $\%$ of locations reached within 24 hours

Figure 5: Response times as a function of the number of hubs.

\subsection{Solutions Patterns}

The top-ranked combinations for one to five hubs obtained through MCDA were provided to the CF and informed their capability planning. Without presenting them here, some patterns emerged in the spatial distribution of hubs. Figure 6 illustrates four notional Arctic subregions that were used to classify the solutions and identify dominant patterns, which are presented in Table 2.

One hub - The top one-hub solutions from the MCDA included a hub in the Mid-Western Arctic. Since the model assumed deployments from the South-East of the country (Petawawa in this example), the most 


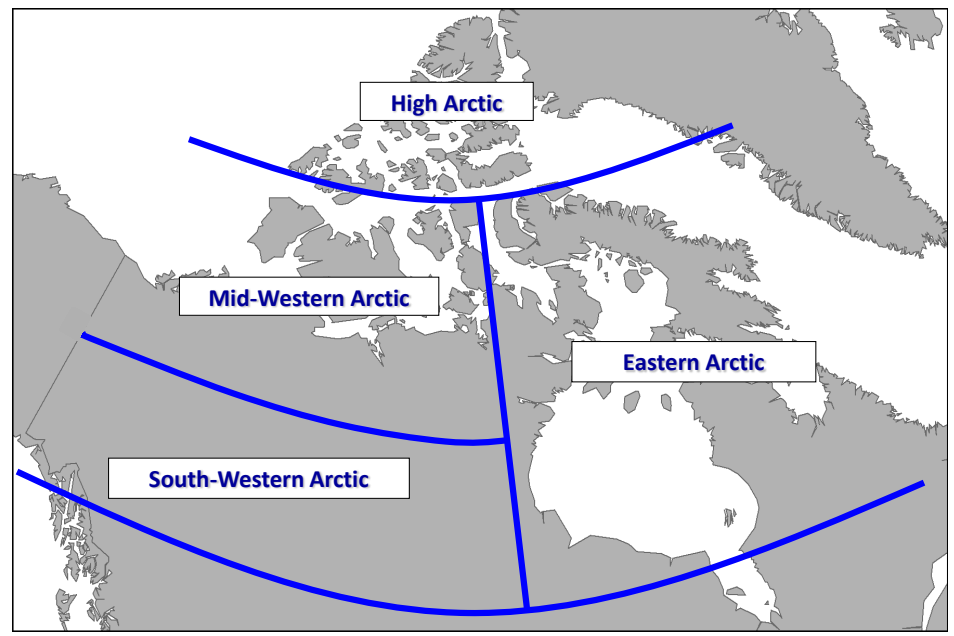

Figure 6: Notional subregions of the North.

Table 2: Main solution patterns for top-ranked hub combinations.

\begin{tabular}{|c|c|c|c|c|}
\hline Pattern & High & $\begin{array}{c}\text { Mid- } \\
\text { Western }\end{array}$ & $\begin{array}{c}\text { South- } \\
\text { Western }\end{array}$ & Eastern \\
\hline \hline 1 & - & 1 hub & - & - \\
\hline \hline $2 \mathrm{a}$ & $1 \mathrm{hub}$ & $1 \mathrm{hub}$ & - & - \\
\hline $2 \mathrm{~b}$ & - & $1 \mathrm{hub}$ & $1 \mathrm{hub}$ & - \\
\hline \hline 3 & $1 \mathrm{hub}$ & $1 \mathrm{hub}$ & $1 \mathrm{hub}$ & - \\
\hline \hline 4 & $1 \mathrm{hub}$ & $1 \mathrm{hub}$ & $1 \mathrm{hub}$ & $1 \mathrm{hub}$ \\
\hline \hline $5 \mathrm{a}$ & 2 hubs & 1 hub & 1 hub & 1 hub \\
\hline $5 \mathrm{~b}$ & 1 hub & 1 hub & 2 hubs & 1 hub \\
\hline
\end{tabular}

challenging locations to reach are in the North-West and that is where operational support capabilities would be the most beneficial.

Two hubs - With two hubs, there are two main solution patterns. Both include one hub in the Mid-Western Arctic. The second hub could be located either in the High Arctic (Pattern 2a) or in the South-Western Arctic (Pattern 2b). Which is best depends on the importance given to different missions. A hub in the High Arctic would be most useful for responding to maritime incidents, which tend to occur at higher latitudes, while a hub in the South-Western Arctic would be more useful for reaching potential air disaster locations since air traffic and SAR event distributions are strongly biased towards the South.

Three hubs - The primary pattern of three hubs included one in all four subregions, except the Eastern Arctic where most locations could still be reached quickly by self-deployed helicopters or other assets from the south-eastern part of the country.

Four hubs - As shown in Figure 5, additional hubs have little effect on the response time to contingencies (criteria 1 to 4 ) but may have utility for SAR or NORAD basing, or for routine deployments not considered by the analysis. Results suggest that a fourth hub would be best located in the Eastern Arctic.

Five hubs - Two dominant patterns with five hubs emerged from the analysis. They both include a hub in all subregions. The only difference between them is where the fifth hub would be added. However, since 


\section{Caron, Gauthier, and Ghanmi}

there is little value added by a fifth hub, the solution patterns are very sensitive to the weights assigned to each decision criteria.

\section{CONCLUSION}

This paper presented how M\&S and MCDA were used in conjunction to assist the CF in further developing their northern operations hub concept. The analysis showed that two or three hubs in the North could reduce the average response time to various contingencies, to a degree that supports further investigation and experimentation of the northern hub concept. Advantageous locations for hubs were identified, taking into account a dozen of criteria related to operational employment and operational support factors.

A number of other decision criteria will be considered as part of future CF planning and offer opportunities for further $M \& S$ work. For example, the sustainment activities occurring after the initial response to an incident in the North could be simulated to refine concepts of operations and potentially make these deployments more cost-effective.

\section{DISCLAIMER}

The reported results, their interpretation, and any opinions expressed therein remain those of the authors and do not represent, or otherwise reflect, any official opinion or position of the Department of National Defence or the Government of Canada.

\section{REFERENCES}

Arctic Council 2009. "Arctic Marine Shipping Assessment 2009 Report”. Accessed Feb. 15, 2012. www. arcticdata.is/data-download.

Bourdon, S. 2005. "Support to Air Force Transformation (Search and Rescue)". DRDC CORA Technical Report 2005-005.

Bourdon, S. 2011. "Optimal Location Method for Canadian Forces Search and Rescue Aircraft Bases". Canadian Operational Research Society Symposium.

Caron, J.-D. and Y. Gauthier 2011. "Comparison of selected deployment schemes for rapid-response operations in the North". DRDC CORA Report LR2011-153.

Caron, J.-D., Y. Gauthier and A. Ghanmi 2012. "Analysis of Northern Hub Locations". DRDC CORA Technical Report (Draft).

Carson, N. and J.-D. Caron 2010. "Canadian NORAD Region Fighter Basing Analysis". DRDC CORA Technical Report 2010-033.

Department of National Defence (DND) 2008. "Canada First Defence Strategy". (Online) http://www. forces.gc.ca/site/pri/first-premier/index-eng.asp.

Department of National Defence (DND) 2010. "Arctic Integrated Concept". ISBN 978-1-100-17289-7.

Department of National Defence (DND) 2011. "Search and rescue statistics for 2010 - Canada Command". Unpublished data.

Environment Canada 2011. "National Climate Data and Information Archive”. Accessed Feb. 15, 2012. www.climate.weatheroffice.gc.ca.

Ghanmi, A. 2010. "Modeling and Analysis of Canadian Forces RSOM Hubs for Northern Operations". Journal of the Operational Research Insight 23:251-274.

Ghanmi, A. 2011. "Optimal RSOM-Hub Location for Northern Operations - A MAJAID Scenario Analysis". DRDC CORA Technical Memorandum 2011-122.

Government of Canada (GoC) 2009. "Northern Strategy". Accessed Feb. 15, 2012. www.northernstrategy. $\mathrm{ca} / \mathrm{cns} / \mathrm{cns}$-eng.asp.

Pelletier, J.-F., and E. Guy 2011. "Evaluation of maritime transportation activities in the Arctic". Accessed Feb. 15, 2012. http://www.arctic-conference.eu/objects/Stockholm/Pelletier.pdf. 


\section{Caron, Gauthier, and Ghanmi}

Public Safety Canada (PSC) 2011a. "Canadian Disaster Database”. Accessed Feb. 15, 2012. www. publicsafety.gc.ca/prg/em/cdd/index-eng.aspx.

Public Safety Canada (PSC) 2011b. "Federal Emergency Response Plan". Accessed Feb. 15, 2012. www. publicsafety.gc.ca/prg/em/_fl/ferp-2011-eng.pdf.

Scales, C. 2007. "Major Air Disaster Response in Northern Canada: Heavy Transport". DRDC CORA Technical Report 2007-016.

Statistics Norway (SN) 2006. "The Economy of the North”. Accessed Feb. 15, 2012. http://www.ssb.no/ english/subjects/00/00/30/sa_economy_north/sa84_en/sa84_en.pdf.

\section{AUTHOR BIOGRAPHIES}

JEAN-DENIS CARON holds a B.Sc. degree in mathematics and a Master degree in applied mathematics and computer science from the Université du Québec à Trois-Rivières in Canada. Since 2002, he has been a Defence Scientist with Defence Research and Development Canada - Centre for Operational Research and Analysis (DRDC CORA). He is currently a member of the Canada Command operational research and analysis team, providing decision-support, quantitative analysis, and modeling and simulation to the Command. His email address is jean-denis.caron@drdc-rddc.gc.ca.

YVAN GAUTHIER is a Defence Scientist with DRDC CORA since 2000. He leads a team of operational research analysts embedded with Canada Command, the $\mathrm{CF}$ organization responsible for $\mathrm{CF}$ operations in Canada and the Western Hemisphere, including operations in assistance to civil authorities. During his career, Mr. Gauthier conducted studies for various CF organizations, including the Royal Canadian Air Force and the Royal Canadian Navy. He also conducted studies for the Royal Navy during a secondment with Dstl Naval Systems in Porstdown West, UK. Mr. Gauthier holds a Master degree in physics from Carleton University, Ontario, Canada. His email address is yvan.gauthier@drdc-rddc.gc.ca.

AHMED GHANMI received a B.Sc. degree in engineering, a Master degree and a Ph.D. in applied mathematics from the University Laval, Quebec, Canada. He is currently a senior Defence Scientist with DRDC CORA. His research interest includes military operations research, logistics and transportation modeling, decision analysis, simulation and optimization problems. Dr. Ghanmi has been leading different international research activities in NATO and technical cooperation programs. His email address is ahmed.ghanmi@drdc-rddc.gc.ca. 